\title{
15. CORING-INDUCED MAGNETIC OVERPRINTS AND LIMITATIONS OF THE LONG-CORE PALEOMAGNETIC MEASUREMENT TECHNIQUE: SOME OBSERVATIONS FROM LEG 160, EASTERN MEDITERRANEAN SEA ${ }^{1}$
}

\author{
Andrew P. Roberts, ${ }^{2}$ Joseph S. Stoner, ${ }^{3}$ and Carl Richter ${ }^{4}$
}

\begin{abstract}
Major fluctuations in paleomagnetic directions were commonly observed from long-core measurements of sediments recovered during ODP Leg 160 . The recovered sediments display large-scale variations in magnetic remanence intensity partly because of the presence of magnetically "enhanced" sapropels. The pass-through long-core measurement is highly sensitive to large changes in remanence intensities. Significant discrepancies between the results obtained from discrete samples and longcore measurements indicate that it is necessary to determine whether the measured magnetic signal arises from geomagnetic field behavior, coring-induced overprints, or artifacts of the long-core measurement. Results of experiments designed to distinguish between these possibilities suggest that there are several factors responsible for the observations. Coring-induced overprints do not appear to be a significant problem: they are usually easily removed at low alternating fields (AFs). In some cases, particularly in the lower part of the record at Site 963, remagnetization is evident in intervals where sediment suck-in occurred during piston coring. The sediments in these intervals have stable and intense nearly vertical magnetizations, probably acquired within the core barrel or drill string. These zones are relatively rare, however, and do not account for many of the observed problems. Discrepancies between the paleomagnetic directions obtained from discrete samples and long-core measurements indicate that major intensity changes are a likely cause of some of the anomalous paleomagnetic directions in the long-core data. Our experiments therefore verify that large-scale remanence intensity changes reduce the usefulness of the pass-through long-core measurement technique in the types of sediments recovered during Leg 160. However, it appears that many of the discrepancies are due to the acquisition of a spurious anhysteretic remanent magnetization that results from the presence of uncancelled off-axis bias fields within the demagnetizing coils of the pass-through magnetometer system. It is therefore necessary to develop a means of more effectively detecting and cancelling bias fields over the entire volume in which cores are $\mathrm{AF}$ demagnetized on the shipboard pass-through magnetometer.
\end{abstract}

\section{INTRODUCTION}

Large-scale variations in paleomagnetic directions were commonly observed from long-core measurements of sediments recovered from the eastern Mediterranean Sea during Ocean Drilling Program (ODP) Leg 160. At many sites, large fluctuations in the inclination, including thick zones of shallow normal or reverse polarity, were evident in zones that biostratigraphic data indicate represent the Brunhes Chron (e.g., Cores 160-963A-6H and $8 \mathrm{H}$ in Fig. 1). The reliability of the results from many of these zones of anomalous magnetization is questionable because fully demagnetized discrete samples commonly did not verify the details of the long-core measurements.

A further complication that affected long-core measurements during Leg 160 was the significant downcore variation in natural remanent magnetization (NRM) intensity observed at the sapropel-bearing Sites 964-973. The sediments recovered during Leg 160 are highly varied in their composition, texture, color, and magnetic properties. Many of the variations in color result from cyclic variations in early diagenetic conditions, which are, in part, influenced by sapropel formation and the subsequent decomposition of the sapropels (Calvert, 1983; Sutherland et al., 1984; Klinkhammer and Lambert, 1989). Significant diagenetic alteration of magnetic minerals, owing to vari-

Emeis, K.-C., Robertson, A.H.F., Richter, C., et al., 1996. Proc. ODP, Init. Repts. 160: College Station, TX (Ocean Drilling Program).

${ }^{2}$ Department of Geology, University of California, Davis, CA 95616, U.S.A. roberts@geology.ucdavis.edu

'Department of Geology, University of Florida, Gainesville, FL 32611, U.S.A

Ocean Drilling Program, Texas A\&M University, 1000 Discovery Drive, College Station, TX 77845-9547, U.S.A. ations in early diagenetic conditions, is known in sediments of the eastern Mediterranean Sea (Dekkers et al., 1994). A major finding of the shipboard paleomagnetic research during Leg 160 was that the sapropels exhibit a significant magnetic "enhancement" relative to the surrounding sediments (Fig. 2). The diagenetically reduced gray sediments that underlie the sapropels are typically extremely weakly magnetized, as would be expected if they had been subjected to magnetite dissolution, which is ubiquitous in sulfate-reducing environments (Canfield and Berner, 1987). Magnetic phases are intimately involved in the natural sequence of reactions related to the decomposition of organic matter in sedimentary environments (cf., Verosub and Roberts, 1995). The significant variations in magnetic properties of these sediments are therefore probably related to variations in redox conditions that appear to have resulted in authigenic/diagenetic formation of a secondary ferrimagnetic phase in many of the sapropel layers, whereas other parts of the sequence have been stripped of much of their detrital magnetic mineral content by dissolution. Remanence intensities commonly decrease by 3 orders of magnitude across the boundary between a sapropel and the underlying gray sediment. The pass-through long-core measurement is highly sensitive to large changes in remanence intensities (Weeks et al., 1993), and the fidelity of the whole-core results was clearly impacted by these variations. It is therefore necessary to determine whether the measured magnetic signal arises from one, or a combination, of several factors, including geomagnetic field behavior, coring-induced overprints, or artifacts of the long-core measurement.

Many of the difficulties described above were observed at most of the sites studied during Leg 160 and tests of different hypotheses related to these problems were conceived and executed at different times. The purpose of this paper is to describe experiments that were designed to account for the observed problems and to attempt to dis- 


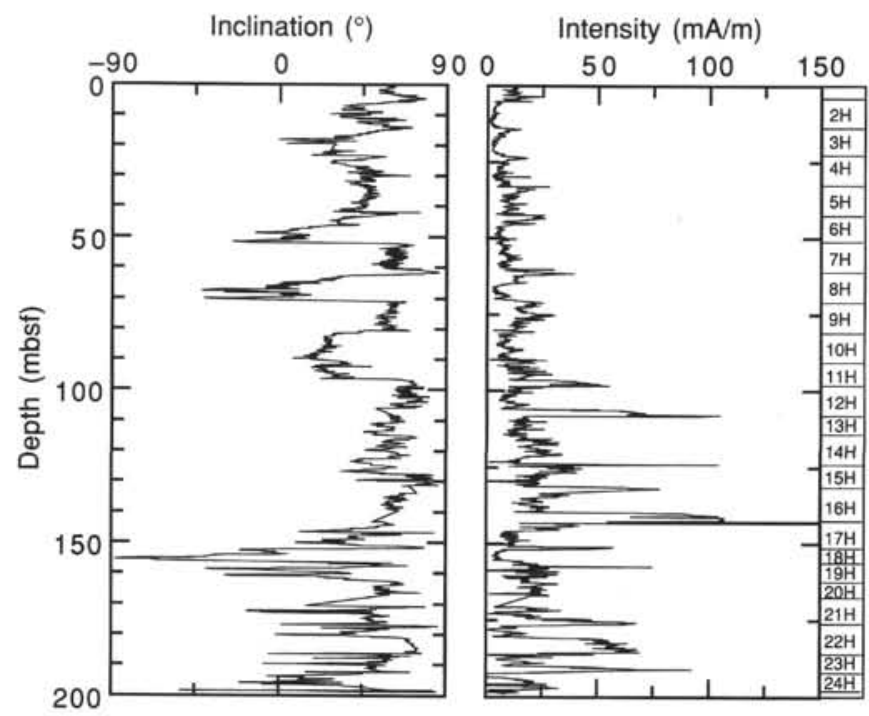

Figure 1. Long-core inclination and intensity records from Hole 963A. This record provides an example of the anomalous inclinations, including shallow normal and reversed polarity directions, observed in many of the records obtained during Leg 160 . The stratigraphic intervals recovered by each core are indicated by numbers in the right-hand column. Discrete-sample data indicate that the Matuyama/Brunhes boundary occurs at about $146 \mathrm{mbsf}$. Biostratigraphic data indicate that the age of sediments from the bottom of Hole $963 \mathrm{~A}$ is about $1.5 \mathrm{Ma}$.

tinguish between coring- and measurement-related complexities and their impact on the quality of the measured results. Many of the problems encountered during Leg 160 will be relevant to other studies of cores recovered and measured with the same techniques. Therefore, we provide here a more coherent and explicit treatment of these phenomena than can be found within the individual site chapters of this volume.

\section{METHODS}

The primary source of paleomagnetic data obtained during Leg 160 was from archive core halves that were measured with a 2-G Enterprises (Model 760-R) pass-through superconducting rock magnetometer. Demagnetization was achieved with in-line alternating field (AF) demagnetizing coils up to maximum peak fields of $25 \mathrm{mT}$. Supplementary data were obtained from discrete samples, which were measured with a Molspin spinner magnetometer and which were stepwise demagnetized with a Schonstedt GSD-1 AF demagnetization unit capable of applying peak fields up to $100 \mathrm{mT}$. In some cases, experiments started during Leg 160 were completed by measurement of additional samples at the Paleomagnetism Laboratory at the University of California, Davis (UC-Davis). Remanence measurements were made on a 2-G Enterprises Model 760-R magnetometer and demagnetization was conducted on a Schonstedt GSD-1 AF demagnetizer. Adjacent samples from homogeneous sediments were measured on board ship as well as at UC-Davis. The directions and intensities obtained are similar, with the results directly comparable between the two laboratories. We will therefore make no distinction between the two groups of samples in the following discussions.

\section{CORING-INDUCED MAGNETIC OVERPRINTS}

Paleomagnetic studies of sedimentary material recovered during many ODP legs have been hampered by coring-induced remagnetizations. For example, on Leg 154, the NRM of the cored sediments

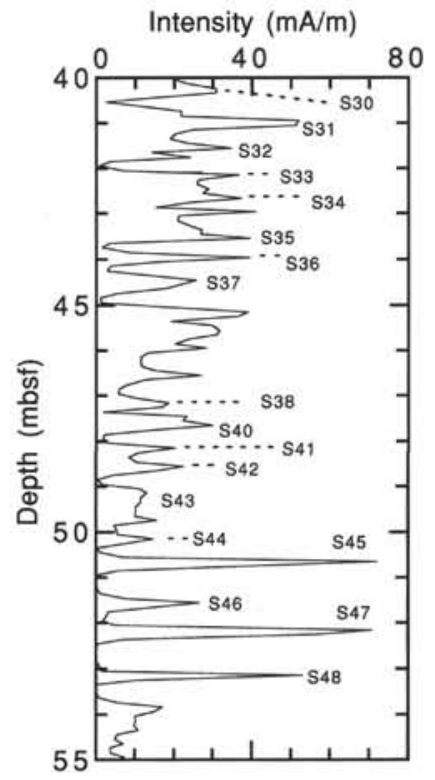

Figure 2. Plot of the long-core intensity record at 40-55 mbsf from Hole 967A. Intensity peaks corresponding to magnetically enhanced sapropels are labelled. The numbering scheme follows that described in the "Lithostratigraphy" section of the "Site 967 " chapter (this volume). There are clearly some intensity peaks that are not associated with sapropels. These peaks are usually associated with mud turbidites, which are common in the sequences recovered during Leg 160.

was characterized by high intensities with a steeply downward-oriented, vertical remanence component (see "Paleomagnetism" section of the Leg 154 Initial Reports site chapters; Curry, Shackleton, Richter, et al., 1995). The vertical component appeared to be an overprint that was partially removed by AF demagnetization at 20 and $30 \mathrm{mT}$, although no characteristic remanence component was isolated at these peak AFs. The declinations also pointed systematically toward $0^{\circ}$. For the majority of sediments cored during Leg 154, the magnetic remanence was directed primarily downcore and into the split face of the core, regardless of whether the measured core material was from an archive half or working half. The same result was observed in cores that were intentionally split at different angles. The origin of this pervasive radial remagnetization was investigated by making magnetic measurements of different elements of the coring system, such as the bottom-hole assembly (BHA) and the advanced hydraulic piston corer (APC) barrel. The various tests indicated that samples can acquire a strong isothermal remanent magnetization (IRM) in these parts of the coring system, as well as in the drill string, but that these IRMs have low coercivity that cannot explain a remagnetization that persists above peak AFs of $30 \mathrm{mT}$ (Curry, Shackleton, Richter, et al., 1995).

Further experiments were made during Leg 157 for which the magnetizations of sediments recovered ranged between those consistent with a depositional origin to those that are evidently controlled by coring-induced radial remagnetizations (Schminke, Weaver, Firth, et al., in press). Measurement of the magnetic fields in the vicinity of extended core barrel (XCB) bits and the APC assembly indicated that the fields can be directed radially outward or radially inward. It was therefore suggested that the radial component of magnetization measured in sediment cores could originate in the field of the drill collar or the drill pipe, with remagnetization occurring as a result of some form of mechanical disturbance associated with coring. The range of behavior observed during Leg 157 indicated that the overprinting was dependent on the mechanical and magnetic properties of the sediment. The more lithified sediments were not so susceptible to coring-induced contamination as the plastic clays and muds 
from higher in the sequence (Schminke, Weaver, Firth, et al., in press). Radial overprints have also been described from cores recovered during Leg 134 (Collot, Greene, Stokking, et al., 1992).

Magnetic overprinting, which is usually different from the radial remagnetization described above, has been commonly reported by paleomagnetists working with Deep Sea Drilling Project and ODP cores. The most common overprint is easily distinguished by its nearly vertical inclination (e.g., Barton and Bloemendal, 1986; Bleil, 1989; Tauxe et al., 1989; Hall and Sager, 1990; Hounslow et al., 1990; Kroenke, Berger, Janecek, et al., 1991; Shibuya et al., 1991). The vertical overprint can have normal (e.g., Bleil, 1989; Hounslow et al., 1990) or reversed polarity (e.g., Weeks et al., 1995) orientations, presumably depending on the magnetization of the elements of the coring system. The drill string, BHA, and core barrel are all known to be strongly magnetized at times (Stokking et al., 1993), and it is likely that most of the overprints reported from ODP cores are acquired as an IRM during coring or during transport of the core barrel up the drill string to the rig floor. The magnetic overprinting may be supplemented by mechanical grain alignment caused by coring-related vibration and fluidization of the cores (Stokking et al., 1993). Numerous measures have been taken over the years to mitigate these problems, including demagnetization of the core barrel. However, the barrel usually becomes strongly magnetized during a single deployment (Stokking et al., 1993); therefore, such measures have met with no success. Investigations of the properties of nonmagnetic core barrels indicate that such materials are not strong enough for use with an APC coring system. Also, there is no alternative to fabricating the drill bits and drill string with strongly magnetic materials. No significant changes have therefore been made to reduce the impact of coring-related magnetic contamination. This situation is justified in recognition that many successful paleomagnetic studies have been made on cores recovered with these methods and that coring-induced remanence components can usually be removed with the appropriate demagnetization techniques.

Because the latitudes of the sites occupied during Leg 160 vary from about $34^{\circ}$ to $37^{\circ} \mathrm{N}$, it is possible to rely exclusively on inclination data for polarity determinations. Furthermore, it is straightforward to distinguish between the directions expected for depositional or postdepositional remanences at these sites, compared to the directions observed for radial remagnetizations and the nearly vertical overprint that is also commonly found in ODP cores.

\section{Coring-induced Magnetic Overprints from Leg 160}

Full stepwise AF demagnetization of discrete samples from all Leg 160 sites indicates the presence of a nearly vertical normal polarity overprint. The overprint, however, is soft and is usually removed at peak fields of about $10 \mathrm{mT}$ (Fig. 3). After removal of this soft overprint, a stable characteristic remanence component is evident for a large proportion of the measured samples (e.g., Fig. 3). The trend of the vector component between 0 and $10 \mathrm{mT}$ was determined on each demagnetization diagram for samples that clearly displayed this overprint. Distributions of these overprint directions are shown in Figure 4 for Holes 963A, 964A, 966A, 967A, and 969A. The overprint directions all have normal polarity and the mean direction is statistically indistinguishable from vertical for each hole (i.e., it is axial to the drill string). The overprint is most likely a low-field IRM that is imparted to the core as it is raised through the drill string. The overprint, therefore, although pervasive, appears to be consistently restricted to coercivities of $0-10 \mathrm{mT}$ (in some cases up to $20 \mathrm{mT}$ ), and the majority of samples usually carry a stable, apparently primary, characteristic remanence at higher demagnetization levels. This observation suggests that it should be possible to obtain reliable paleomagnetic information from these sediments, at least from discrete samples.

Because steep inclinations were observed throughout the coercivity spectrum in numerous discrete samples from the first site studied during Leg 160 (Site 963), we suspected that a more pervasive remagnetization may be present, such as that reported from Leg 154. We therefore undertook a test outlined in the "Paleomagnetism" section of the "Site 925" chapter (Curry, Shackleton, Richter, et al., 1995), whereby five discrete samples were taken from a single whole-round core sample, to determine whether the core had been radially remagnetized. Our test was negative. Subsequent measurements of discrete samples from the remainder of the sites studied during Leg 160 confirmed that the drill-string overprint is consistently soft and that stepwise demagnetization of discrete samples is usually effective in isolating a characteristic remanence direction that is consistent with a depositional or postdepositional origin.

\section{Studies of Zones of Sediment Suck-in from Leg 160}

Despite this result, data from Site 963 suggest the possibility that the coring process had somehow interfered with the magnetization, at least within restricted stratigraphic intervals. Site 963 is the only site from which relatively homogeneous sediment (dominantly calcareous nannofossil clay) was obtained during Leg 160 . The first hint that there may be problems with this record becomes evident when the long-core inclination record is plotted with the core breaks shown alongside (Fig. 1). Major inclination excursions to shallow normal or reverse polarity are evident at the base of several of the cores, most notably $6 \mathrm{H}$ and $8 \mathrm{H}$. Other, less marked, changes in inclination are also evident at many other core boundaries.

Because of the massive nature of the recovered sediment, visual evidence of sediment disturbance was not found during shipboard examination and description. More detailed examination of the cores was carried out post-cruise, in an attempt to determine the cause of the anomalous magnetic directions. This examination indicated the presence of zones of sediment with vertical suck-in features at the bottom of several cores from the lower part of the sequence (160$963-12 \mathrm{H}, 14 \mathrm{H}$, and $16 \mathrm{H})$.

We collected samples from several zones of core suck-in identified during Leg 160 and measured the remanence in order to determine whether these zones could be distinguished from undisturbed sediments on the basis of their remanence characteristics. An example of a zone of suck-in from a core containing a contrast in sediment texture is shown in Figure 5.

The stability of the demagnetized NRM from zones of suck-in varied from site to site. Twelve samples were subjected to full stepwise AF demagnetization from suck-in zones from Holes $963 \mathrm{~A}$ and 963B. These samples were all extremely stably magnetized throughout the entire coercivity spectrum from 0 to above $90 \mathrm{mT}$, with a nearly vertical inclination, variable declinations, and no secondary remanence component (Fig. 6). Similar directions were observed at other sites, including Site 968 . Site 967 is the only site from which samples from suck-in zones were not stably magnetized. At this site, a soft, steep component that accounts for more than $90 \%$ of the NRM intensity is removed between 0 and $10 \mathrm{mT}$, but at higher peak AFs, no stable direction is isolated. This behavior is probably due to the particular assemblage of magnetic grains at Site 967. Nevertheless, the observation that a highly stable remanence is preserved in the majority of sediments from suck-in zones indicates that the remanence acquisition mechanism is extremely efficient. A good analog for this type of remanence is probably the stirred remanent magnetization (StRM) described by Tucker (1980) and Payne and Verosub (1982). The StRM was probably acquired when the strong vertical suck exerted by the piston corer in semicompacted sediments caused the sediment to flow turbulently into the core in the presence of an ambient field that is dominated by the vertical field component in the core barrel and the drill string.

The nearly vertical characteristic remanence direction in these suck-in zones is distinct from the expected inclination of $50^{\circ}-55^{\circ}$ at the latitudes of the studied sites. It should also be noted that the remanence intensities of samples from these zones are anomalously high, 
Figure 3. Representative vector component demagnetization diagrams of samples from cores recovered during Leg 160 that display the intense, vertical drillstring overprint. Open (solid) symbols indicate projections onto the vertical (horizontal) plane. Insets are plots of intensity (normalized to the NRM value) vs. demagnetization level. Demagnetization levels are shown for each sample at the base of each plot. A. Sample 160-963A-17H-2, $82 \mathrm{~cm}$ (normal primary polarity); B. Sample 160-963A-17H-5, $78 \mathrm{~cm}$ (reverse primary polarity); C. Sample 160-964A-2H1, $59 \mathrm{~cm}$ (normal primary polarity); D. Sample 160$966 \mathrm{~A}-6 \mathrm{H}-4,39 \mathrm{~cm}$ (reverse primary polarity); E. Sample 160-967A-1H-3, $70 \mathrm{~cm}$ (reverse primary polarity); F. Sample 160-969A-10H-2, $37 \mathrm{~cm}$ (normal primary polarity).
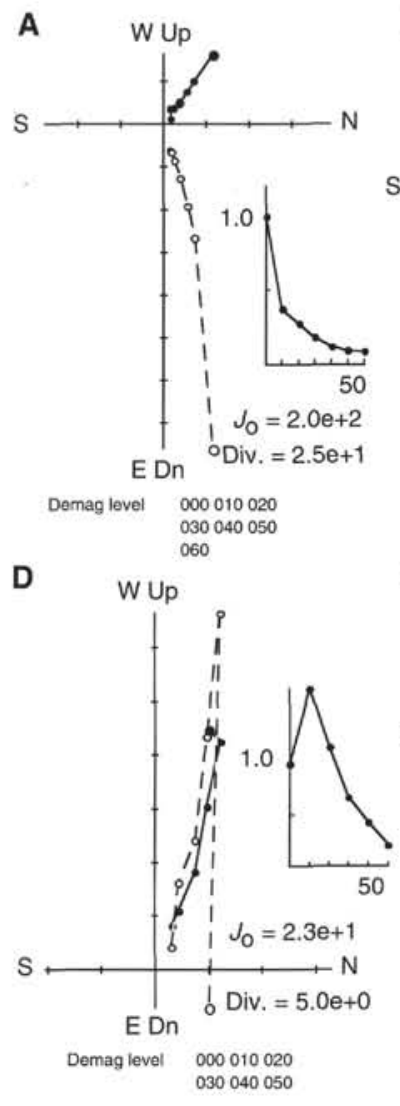

C W Up

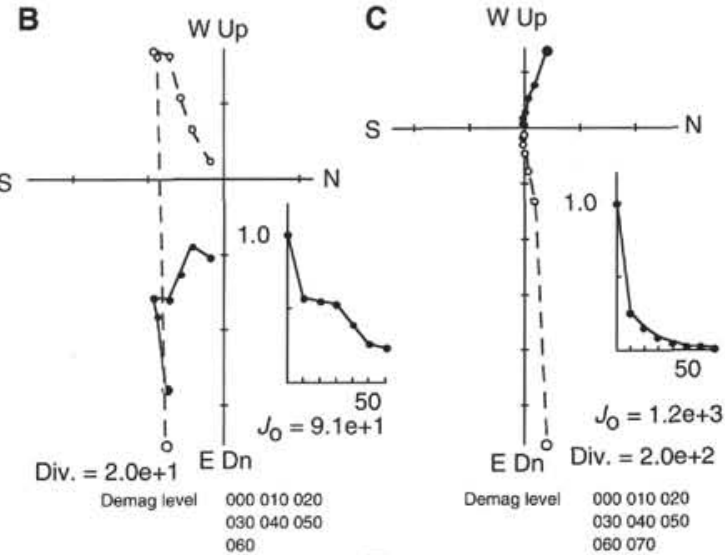

E
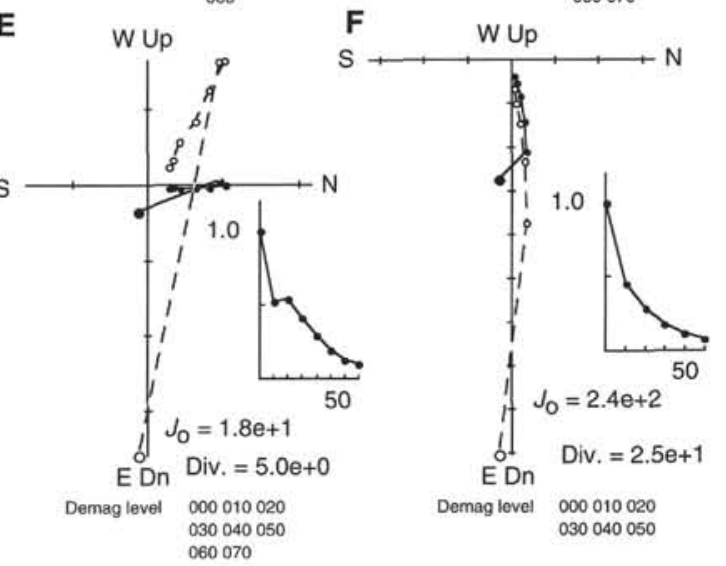

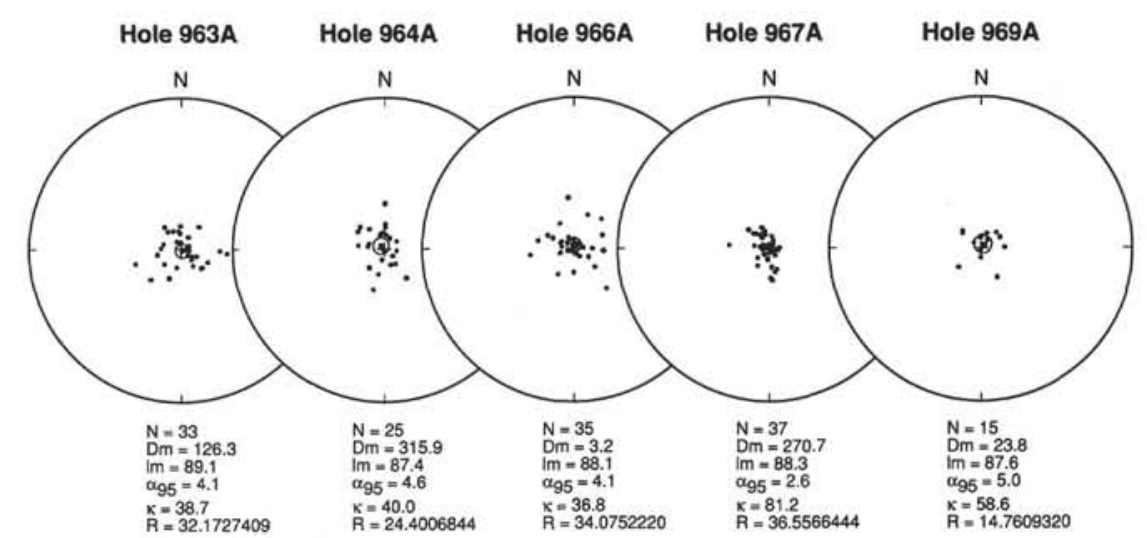

Figure 4. Paleomagnetic directions from the low-coercivity drill-string overprint (determined by linear regression from 0 - and $10-\mathrm{mT}$ demagnetization data in vector component plots for $\mathrm{N}$ stepwise-demagnetized samples) plotted on equal-area stereographic projections for samples from Holes 963A, 964A, 966A. $967 \mathrm{~A}$, and 969A. The symbols represent projections onto the upper hemisphere. $\mathrm{Dm}=$ mean declination, $\mathrm{Im}$ $=$ mean inclination, $\alpha_{95}=95 \%$ cone of confidence about the mean direction, $\kappa=$ Fisher's precision parameter, and $\mathrm{R}=$ sum of each unit vector shown in the figure. Declinations were corrected to geographic coordinates with orientation data derived from the Tensor orientation tool.

compared to the surrounding sediment. This is evident in the wholecore intensity profile (Fig. 1), where high intensities occur in the lower parts of the cores in which significant suck-in has occurred (e.g., $160-963-12 \mathrm{H}, 14 \mathrm{H}, 16 \mathrm{H}$, and $22 \mathrm{H})$. All zones with nearly vertical characteristic remanence in the homogeneous sediments of Site 963 must therefore be treated with caution: the most likely explanation for this behavior is remagnetization owing to suck-in effects. The thick zone of apparently consistent normal polarity inclinations between 180 and $187 \mathrm{~m}$ below seafloor (mbsf) in Core 160-963A-22H (Fig. 1) is therefore interpreted as a zone that has been remagnetized during core suck-in. Zones of core suck-in can also be detected in downhole plots of magnetic susceptibility because the suck-in process usually homogenizes the sediment, producing markedly decreased susceptibility variations. However, we have found that, for the sediments studied during Leg 160, the occurrence of nearly vertical inclinations is the most diagnostic discriminant of core suck-in. The above data therefore clearly demonstrate that paleomagnetism can play an important role in detecting zones of suck-in within homogeneous sediments where identification of coring-induced complexities cannot be made easily by visual inspection.

Core suck-in was not an important problem at other sites recovered during Leg 160 because the other sequences contain sufficient lithologic variation that suck-in was easily detected. APC recovery was immediately abandoned when the stratigraphic integrity of a sequence was compromised by this coring effect.

The evidence for coring-induced remagnetization described above accounts satisfactorily for zones with anomalously steep inclinations and relatively high intensities, but it does not account for the shallow normal and reversed inclinations observed at the base of Cores $6 \mathrm{H}$ and $8 \mathrm{H}$ in Hole 963A. These anomalous magnetizations are most likely due to an unexplained coring-induced effect because the boundaries of the zones of anomalous magnetization occur at core 


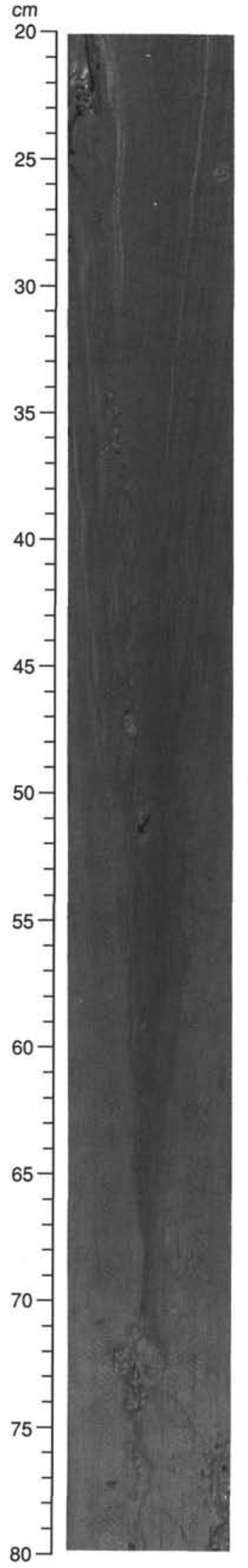

Figure 5. Photograph of core section in which there is sufficient sediment textural contrast to show visible evidence of core suck-in (Section 160-963B$20 \mathrm{H}-6,20-80 \mathrm{~cm}$ ).

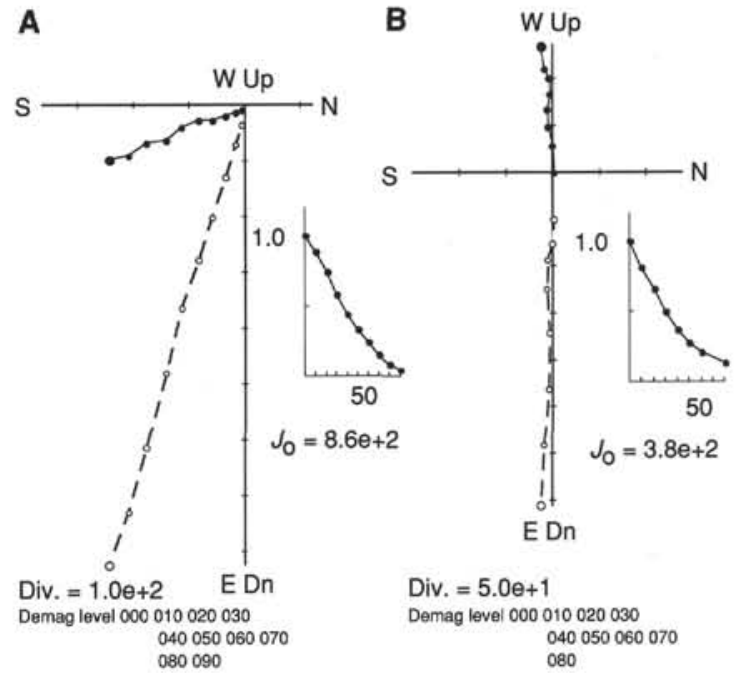

Figure 6. Representative vector component demagnetization diagrams of samples from core sections in which the sediment was sucked-in during coring. A. Sample 160-963A-12H-7, 34 cm; B. Sample 160-963B-15H-5, 79 $\mathrm{cm}$. The two samples have similar coercivity distributions. Note that (A) was stepwise demagnetized to $90 \mathrm{mT}$ and that (B) was stepwise demagnetized to $80 \mathrm{mT}$. Symbols are the same as in Figure 3.

breaks. If these zones have been affected by an unknown coring-induced remagnetization, the manifestation of this effect is clearly different from the nearly vertical overprints and remagnetizations that are dominant with this type of coring. This observation suggests that more subtle types of coring-induced paleomagnetic problems for which there is presently no adequate explanation may occur in cores obtained with the APC method.

\section{LIMITATIONS OF THE LONG-CORE MEASUREMENT TECHNIQUE}

The long-core measurement technique is the only feasible way of rapidly measuring the large volumes of material recovered during many ODP legs. Useful results are critically dependent on the reliability of the measurement. The large diameter of the access of the shipboard magnetometer $(7.6 \mathrm{~cm})$ allows measurement of split cores of up to $1.5 \mathrm{~m}$ in length; however, the geometrical constraints imposed by this large diameter mean that the pick-up coils in the magnetometer have broad response curves (Fig. 7) that result in low spatial resolution. Usually, the half-power width of the response curve is taken as a measure of the maximum spatial resolution of the pick-up coils (Weeks et al., 1993). Because a large volume of material contributes to the measured magnetization at a point along a sediment core, the magnetization will represent a convolution of the magnetometer response function with the true magnetization of the core (Constable and Parker, 1991). In effect, the resultant magnetization at each measurement point will appear to be smoothed over a stratigraphic interval of about $15 \mathrm{~cm}$.

The shape of the response curves has important implications for the long-core measurement (cf., Weeks et al., 1993). As can be seen on Figure 7, the response curves for the transverse axes are different from that of the axial axis. As a dipole point source is passed through the pick-up coils, the transverse coils first give a negative response, corresponding to the back-field of the dipole at a distance. The coils then give the main central positive response, followed by another negative lobe as the dipole passes through the other side of the pickup coils. The axial response is simpler and does not have regions of negative response. The negative lobes of the transverse coils can be corrected for and the correct intensities can be determined by normal- 


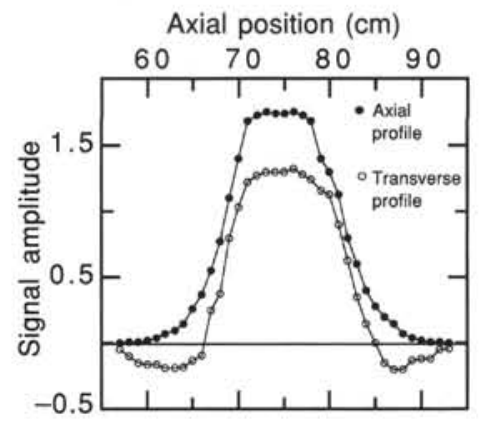

Figure 7. Comparison of the axial and transverse response curves for the shipboard 2-G Enterprises Model 760-R superconducting rock magnetometer. These curves were obtained by passing a dipole point source through the sensor region. The transverse profile has negative lobes that are not present on the axial response. The half-power width of the sensors is about $15 \mathrm{~cm}$.

izing by the area under the response curve (Weeks et al., 1993). This correction is automatically applied by the shipboard computer software. However, this correction works adequately only for homogeneously magnetized cores.

Weeks et al. (1993) have noted that in a core in which significant changes exist in remanence intensity, the effect is more complicated. These workers simulated a twofold increase in remanence intensity, with no change in direction, convolved with an appropriate response function, and produced anomalous inclination values at the region of major intensity change. The true inclinations were recorded in the zones where the intensity was held constant. The anomalous inclinations are attributed to the negative lobes on the transverse axes which, because the ratio of axial to transverse moment varies with intensity changes, will produce an inclination signal that was not present in the original magnetization. This effect has been observed beyond the half-power width distance. The relative complexity of the transverse with respect to the axial response curves is therefore an important determinant in producing spurious effects in cores with major changes in remanence intensity. The results of Weeks et al. (1993) clearly demonstrate that care must be exercised in interpreting long-core records that contain major changes in remanence intensity.

\section{Results from Leg 160}

As noted above, it was observed that remanence intensities are typically high within sapropels and that they can decrease by 3 orders of magnitude across the boundary between a sapropel and the underlying gray sediment. Large swings in declination and inclination usually accompany such major changes in remanence intensity (Fig. 8). Remanence was measured routinely at $10-\mathrm{cm}$ intervals, and major variations in remanence direction are clearly visible on such low-resolution records (e.g., Fig. 8A). However, in order to examine the effects of intensity changes in greater detail, remanence was sometimes measured at 2-cm intervals on selected core sections (e.g., Fig. 8B). To determine how much of the measured signal is an artifact of the measurement technique, it is necessary to perform a deconvolution of the measured signal.

\section{Artificial Simulation of the Effects of Intensity Change on the Long-core Record}

It is well known that the commonly used deconvolution techniques can introduce spurious frequencies into a studied record (Constable and Parker, 1991). To avoid this problem, we made a comparison between a deconvolved and a convolved signal by inputting a known signal to see how it is convolved by the response func- tion of the magnetometer. These experiments were conducted to simulate major changes in remanence intensity to examine the possible effects of sapropels on the long-core measurement.

Discrete samples with known remanence directions and intensities were placed end-to-end on a specially designed sample holder and were measured in the pass-through mode. By using discrete samples that had been fully demagnetized, and on which a wide array of mineral magnetic studies had already been performed, it was possible to select samples with IRMs that varied over almost 2 orders of magnitude because of significant variations in magnetic mineral concentration. Similar remanence directions were imposed on a set of discrete samples by imparting successively weaker IRMs to the three mutually orthogonal sample axes. Applied fields of 300,10 , and 5 $\mathrm{mT}$ were applied to the $\mathrm{z}, \mathrm{x}$, and $\mathrm{y}$ sample axes, respectively. The direction and intensity of the composite magnetization of each sample was measured on a Molspin spinner magnetometer. The samples were then placed end-to-end to produce a smoothly varying intensity curve, on which major instantaneous changes were superimposed. The remanence directions were kept relatively uniform, although a major inclination excursion was made to accompany one of the large intensity changes to investigate the effects of intensity and direction change on the long-core record.

The results of this experiment are shown in Figure 9. To first order, the long-core magnetometer gives an excellent reproduction of the directional features of the discrete-cube-train record. However, a major $\left(180^{\circ}\right)$ declination excursion is produced in the long-core measurement at $58 \mathrm{~cm}$, which corresponds to the zone of decreasing intensity immediately below the 2-orders-of-magnitude increase in intensity at $50 \mathrm{~cm}$. The low-intensity zone is only $10 \mathrm{~cm}$ thick, but the position of the spurious declination excursion is offset slightly from the position of the major intensity change. This confirms the observation of slight downcore displacements of anomalous declinations with respect to major intensity changes in the whole-core records shown in Figure 8B. Because the axial component of magnetization is dominant in the cube-train samples, the inclinations are steep $\left(60^{\circ}-\right.$ $80^{\circ}$ ) and it is much easier to produce spurious declinations than inclinations by varying the remanence intensity. If we had imparted a magnetization with inclinations similar to those expected at the sampling localities $\left(50^{\circ}-55^{\circ}\right)$, it would have been easier to produce spurious inclinations, as observed by Weeks et al. (1993).

A real declination excursion, centered at $118 \mathrm{~cm}$, is faithfully detected by the long-core measurement, although, as expected, it is somewhat smoothed (Fig. 9). A real inclination excursion, centered at $93 \mathrm{~cm}$, is significantly attenuated because the width of the excursion is about the same as the half-power width of the response curve $(15 \mathrm{~cm})$. A part from this attenuation, the long-core measurement has faithfully reproduced the rather noisy inclination record. Significant attenuation is also evident in the intensity records. The intensities in the low-intensity zones of the long-core record are not as low as in the discrete-sample record because the intensity lows are narrow with respect to the half-power width of the magnetometer pick-up coils. This suggests that the experiment is not entirely realistic because we did not have sufficient samples available to reproduce the broad (usually $50 \mathrm{~cm}$ thick) intensity lows that occur in the zones of reduced sediment below the sapropels. Clearly, these zones are much thicker than the width of the magnetometer response functions, and a more realistic measurement of the intensity of these zones will be obtained with long-core measurements of real sediments than in our experiment. Although artificial simulations of this type can clearly teach us something useful about the long-core measurement technique, time limitations prevented us from making more realistic simulations of the effects of major intensity changes on long-core records. It is clear from the work of Weeks et al. (1993) and from our observations of long-core records that significant changes in declination and inclination commonly accompany major changes in intensity, as seen in the records shown in Figure 8. 


\section{A}
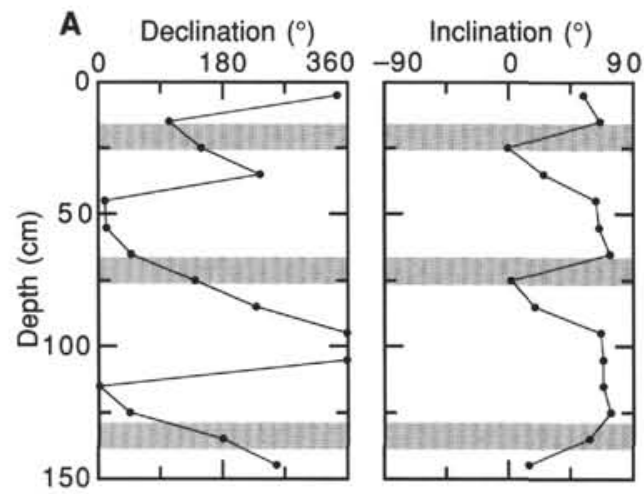

Intensity $(\mathrm{mA} / \mathrm{m})$
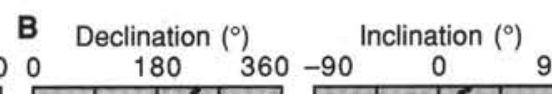

Intensity $(\mathrm{mA} / \mathrm{m})$
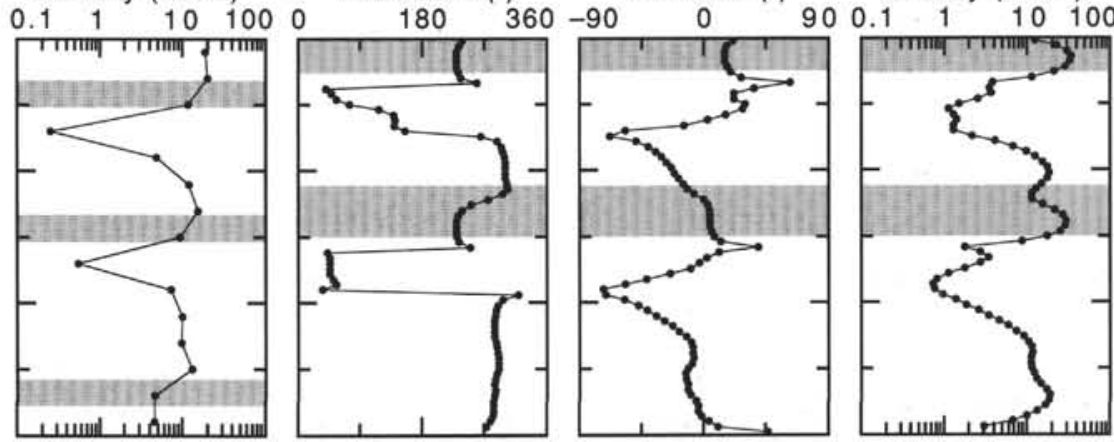

Figure 8. Declination, inclination, and intensity records for (A) Section 160-967A-7H-6, with a measurement interval of $10 \mathrm{~cm}$, and (B) Section 160-971C-2H5 , with measurement interval of $2 \mathrm{~cm}$. Sapropels are indicated by the shaded regions. The zones of high intensity associated with the sapropels are better illustrated in (B), where the measurement density is higher.

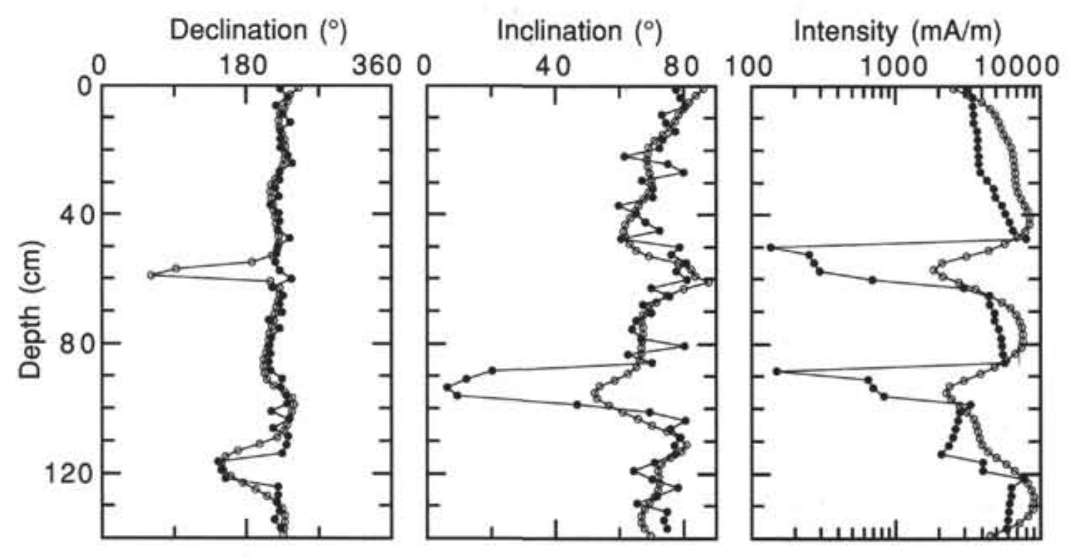

Figure 9. Declination, inclination, and intensity records obtained for the cube-train experiment. Solid symbols represent data from individual discrete samples. Open symbols represent long-core measurements made at 2 -cm intervals on the shipboard pass-through cryogenic magnetometer of the discrete-sample-cube train (see text for explanation).

\section{Comparison of Detailed Discrete-sample and Long-core Measurements from Hole 973B}

A more effective test than the simulation described above is to make paleomagnetic measurements of a continuous set of discrete samples from the working half of a core from which major intensity changes had been observed on the archive core half. We obtained a dedicated mudline core and made detailed measurements on Sections $160-973 \mathrm{~B}-1 \mathrm{H}-1$ and $1 \mathrm{H}-2$ to perform this test. Observations during Leg 160 indicated that the magnetic remanence of sapropel samples undergoes significant decay with time, so we first concentrated on fully measuring samples from sapropels, followed by samples from the normal pelagic sediment. We were unable to complete the measurements before the end of Leg 160 and the remaining pelagic sediment samples were measured at the Paleomagnetism Laboratory at UC-Davis.

Results of the long core and discrete sample comparison are shown in Figure 10. All discrete-sample data are from stably magnetized samples, and the remanence directions were determined by linear regression fits to multiple demagnetization points. The intensities of the discrete samples at $25 \mathrm{mT}$ are much more variable than those of the long-core record, but most of the general features, including the intensity values, of the discrete-sample record are reproduced in the long-core record. This general agreement between the two data sets suggests that both records are of high quality.

The stable remanence directions derived from the discrete samples are relatively uniform and display variations that are consistent with normal secular variation. It is immediately evident that there are significant differences between the declinations and inclinations from the two types of measurement. The differences observed between the long-core and discrete-sample measurements must result either from the measurement process itself or from sampling-induced disturbance. Hailwood et al. (1989) showed that the discrete-sampling methods used (i.e., pushing plastic boxes into sediment) can induce significant anisotropy along the direction of push. This method can also influence the remanence properties of the sampled sediment. Given that the discrete samples taken from Hole 973B have relatively large volumes $\left(7 \mathrm{~cm}^{3}\right)$ and that they appear to faithfully record expected geomagnetic field directions, we have no a priori reason to suspect the validity of the discrete-sample results. We therefore assume that the discrepancies between the long-core and discrete-sample data shown in Figure 10 result from the long-core measurement process.

In the vicinity of the intensely magnetized sapropels, the longcore and discrete-sample data are generally in excellent agreement. The largest deviations of the long-core directional data from the discrete-sample data, particularly in the inclinations, occur within the zones of gray diagenetically reduced mud between the sapropels (e.g., 90-118 cm and 136-180 cm; Fig. 10). These zones are associated with major changes in remanence intensity and it is likely that the intensity changes are responsible for at least some of the measured discrepancies in these zones. The occurrence of major intensity changes provides strong evidence that much of the directional fluctuation observed in the vicinity of sapropels may be an artifact of the long-core measurement technique. However, it does not explain the discrepant long-core inclinations at the top of Hole 973B (Fig. 10), which occur within a zone of relatively constant intensity $(0-60 \mathrm{~cm})$ that is well above the $15-\mathrm{cm}$ half-power width in which there may be an effect from the underlying sapropels at $62-91 \mathrm{~cm}$.

The observation that the discrete-sample data faithfully record paleomagnetic directions that are consistent with those expected at the site indicates that the most likely explanation for the discrepancy is 
Figure 10. Declination, inclination, and intensity records for Hole 973B. Closed symbols represent long-core measurements after demagnetization at $25 \mathrm{mT}$, whereas open symbols represent data from stepwise-demagnetized discrete samples. Declinations and inclinations were determined from linear regression fits to multiple demagnetization steps, whereas the intensity corresponds to the values at $25 \mathrm{mT}$. Sapropels are indicated by the shaded regions.
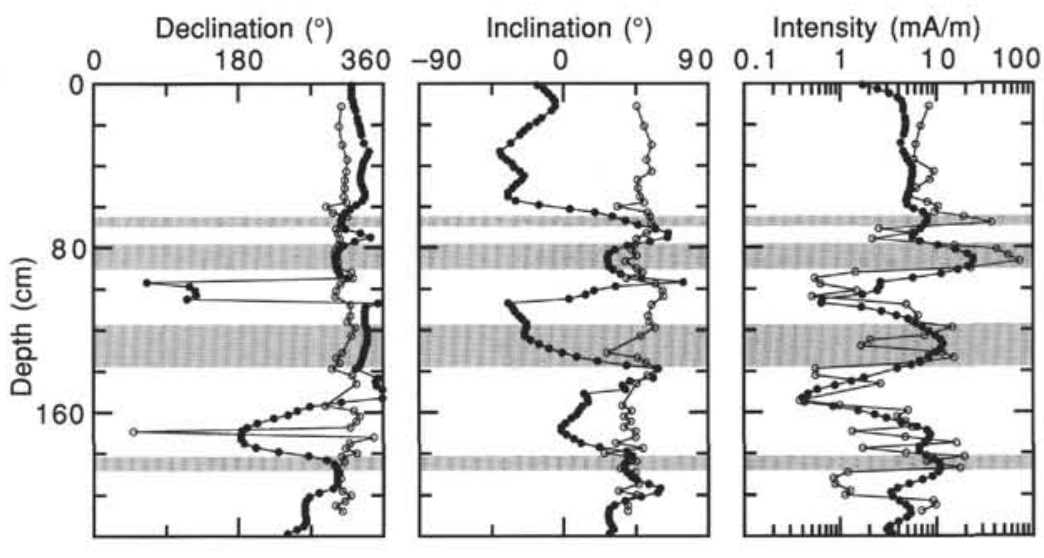

associated with the long-core measurement. It is necessary to consider other aspects of the long-core measurement process because it is clear that large-scale intensity variations alone cannot give rise to the large discrepancy shown in Figure 10. The long-core measurement system utilizes an in-line AF demagnetization system. With this system, a constant peak AF is applied with one demagnetizing coil at a time and movement of the core through the $\mathrm{AF}$ at a constant rate results in AF demagnetization because the field decays, eventually to zero, with increasing distance from the coil. This is in contrast to the "static" system, used to demagnetize discrete samples, in which the sample remains in a fixed position while the field itself decays. It is well known that the presence of a DC bias field within a demagnetizing coil can produce a spurious anhysteretic remanent magnetization (ARM). With the discrete-sample demagnetizer, the coil lies in a zone that is sufficiently shielded that the acquisition of spurious ARM's can be avoided. Maintaining a sufficiently small field to avoid ARM acquisition within the demagnetizing coils of the longcore system is more difficult because it is much less easy to maintain "zero" field over such a large volume of core during demagnetization.

The dynamic and electromagnetically noisy shipboard environment also makes difficult the maintenance of such shielding. During Leg 160 , we vigilantly monitored a single-axis (axial) fluxgate magnetometer to maintain a low field within the shields that house the inline demagnetizing unit. If the field increased unacceptably, nulling coils were used to reduce the field. Significant bias fields often arose during periods of concentrated activity on the rig floor, particularly during tripping of drill pipe, and when the ship made a change in bearing during transits, presumably owing to magnetic flux leakage between the ends of the shields that house the demagnetizing coils. The long-core inclinations shown in Figure 10 clearly have a significant transverse component, as reflected in the shallow reverse polarity inclinations. The single-axis (axial) fluxgate sensor is clearly unable to detect transverse field components and the most promising explanation that accounts for the long-core measurement problems encountered during Leg 160 is that spurious off-axis ARM's were acquired during pass-through AF demagnetization. Variations in susceptibility to ARM acquisition, which would be expected in nonhomogeneously magnetized sediments such as those recovered during Leg 160, may also contribute partially to the significant downcore variations in paleomagnetic directions.

Despite the possibility that the variability in the long-core inclination records may result from acquisition of spurious ARM's as a result of changes in off-axis bias fields in the pass-through demagnetizing system, it is clear that the large variations in remanence intensity of the sediments recovered during Leg 160 make this material far from ideal for long-core paleomagnetic measurements. The experimental observations made here demonstrate the limitations of the long-core paleomagnetic measurement technique, which is implicitly designed to operate optimally in cores that are relatively homogeneously magnetized.

\section{CONCLUSIONS}

Experiments conducted to determine the cause of the highly variable quality of long-core paleomagnetic records obtained during Leg 160 suggest that there are several factors responsible for the observations. Coring-induced overprints appear to be a minor problem and, in most cases, are easily removed at low AFs and are easily differentiated from the characteristic remanence component caused by depositional or postdepositional processes. Thus, although the long-core data are often of poor quality, post-cruise magnetostratigraphic studies on discrete samples should be successful.

We have seen no evidence of the pervasive radial remagnetization that has been observed in several recent ODP legs. In some cases, particularly in the lower part of the record at Site 963, sediment suckin occurred during piston coring. The sediments in these intervals have stable and intense nearly vertical magnetizations, probably acquired within the core barrel or drill string, that are suggestive of a highly efficient remanence acquisition mechanism such as a stirred remanent magnetization. Paleomagnetism therefore provides an excellent means of identifying zones of sediment suck-in where visual examination is unable to identify such zones owing to lithologic homogeneity. Clearly, this method will be more successful at mid- and low-latitude sites, where there is sufficient contrast between the vertically oriented remagnetization and the shallower inclination expected for a depositional or postdepositional remanence at the site latitude.

Significant variations in remanence intensity can clearly cause artifacts in long-core measurements. Discrepancies between the paleomagnetic directions obtained from a continuous line of discretesample and long-core measurements confirm the suggestion that major intensity changes are a likely cause of some of the anomalous paleomagnetic directions in the long-core data. Our experiments therefore verify that large-scale intensity changes reduce the usefulness of this technique in the types of sediments recovered during Leg 160. Deconvolution at the half-width resolution would help to obtain the correct measurement and should not increase the effects of noise because there is no attempt to gain resolution with such a measure. However, as pointed out by Constable and Parker (1991), the best solution is to make a better experiment by reducing the half-power width of the magnetometer response coils. This is clearly not possible with the wide-access magnetometers necessary for whole-core measurements. It is therefore likely that future legs that encounter highly variable remanence intensities will experience similar measurement artifacts as those encountered on Leg 160, although minimal deconvolution may help to produce cleaner records. 
Most of the discrepancies observed in the records presented here appear to be caused by the acquisition of spurious ARM's during pass-through AF demagnetization. The ARM's probably result from significant uncancelled off-axis bias fields within the in-line demagnetizing unit. It is therefore necessary to have a better means of detecting, and cancelling, bias fields (particularly nonaxial fields) with the demagnetizing unit on the shipboard pass-through magnetometer. Measures should also be made to monitor and maintain "zero" field over the entire volume of core that is being demagnetized because maintaining "zero" field at a single point in the coil array does not guarantee that bias fields do not occur elsewhere in the array. This is not a simple problem in the electromagnetically noisy and dynamic shipboard environment, but given the importance of obtaining reliable paleomagnetic measurements, every effort should be made to address this problem.

\section{ACKNOWLEDGMENTS}

We are grateful to Margaret Hastedt for her high quality technical support of our paleomagnetic studies during Leg 160; Mike Fuller and Robin Weeks, who provided insightful reviews of an earlier version of this manuscript; and William Goree for providing the data presented in Figure 7.

\section{REFERENCES}

Barton, C.E., and Bloemendal, J., 1986. Paleomagnetism of sediments collected during Leg 90, Southwest Pacific. In Kennett, J.P., von der Borch, C.C., et al., Init. Repts. DSDP, 90: Washington (U.S. Govt. Printing Office), 1273-1316.

Bleil, U., 1989. Magnetostratigraphy of Neogene and Quaternary sediment series from the Norwegian Sea: Ocean Drilling Program, Leg 104. In Eldholm, O., Thiede, J., Taylor, E., et al., Proc. ODP, Sci. Results, 104: College Station, TX (Ocean Drilling Program), 829-901.

Calvert, S.E., 1983. Geochemistry of Pleistocene sapropels and associated sediments from the Eastern Mediterranean. Oceanol. Acta, 6:225-267.

Canfield, D.E., and Berner, R.A., 1987. Dissolution and pyritization of magnetite in anoxic marine sediments. Geochim. Cosmochim. Acta, 51:645659

Collot, J.-Y., Greene, H.G., Stokking, L.B., et al., 1992. Proc. ODP, Init. Repts., 134: College Station, TX (Ocean Drilling Program).

Constable, C.G., and Parker, R.L., 1991. Deconvolution of long-core palaeomagnetic measurements, spline therapy for the linear problem. Geophys. J. Int., 104:453-468.

Curry, W.B., Shackleton, N.J., Richter, C., et al., 1995. Proc. ODP, Init. Repts., 154: College Station, TX (Ocean Drilling Program).

Dekkers, M.J., Langereis, C.G., Vriend, S.P., van Santvoort, P.J.M., and de Lange, G.J., 1994. Fuzzy $c$-means cluster analysis of early diagenetic effects on natural remanent magnetization acquisition in a 1.1 Myr piston core from the Central Mediterranean. Phys. Earth Planet. Inter., 85:155171.

Hailwood, E.A., Stumpp, C., and Zukin, J., 1989. Soft sediment sampling errors in palaeomagnetic and magnetic fabric data. Bull. Int. Assoc. Geomagn. Aeron., 53:199. (Abstract)

Hall, S.A., and Sager, W.W., 1990. Paleomagnetic and rock magnetic properties of sediment samples from Ocean Drilling Program Leg 116, central Indian Ocean. In Cochran, J.R., Stow, D.A.V., et al., Proc. ODP, Sci. Results, 116: College Station, TX (Ocean Drilling Program), 337-344.

Hounslow, M.W., Bootes, P.A., and Whyman, G., 1990. Remanent magnetization of sediments undergoing deformation in the Barbados accretionary prism: ODP Leg 110. In Moore, J.C., Mascle, A., et al., Proc. ODP, Sci. Results, 110: College Station, TX (Ocean Drilling Program), 379-391.

Klinkhammer, G.P., and Lambert, C.E., 1989. Preservation of organic matter during salinity excursions. Nature, 339:271-274.

Kroenke, L.W., Berger, W.H., Janecek, T.R., et al., 1991. Proc. ODP, Init. Repts., 130: College Station, TX (Ocean Drilling Program).

Payne, M.A., and Verosub, K.L., 1982. The acquisition of post-depositional detrital remanent magnetization in a variety of natural sediments. Geophys. J. R. Astron. Soc., 68:625-642.

Schminke, H.-U., Weaver, P.P.E., Firth, J.V., et al., in press. Proc. $O D P$, Init. Repts, 157: College Station, TX (Ocean Drilling Program).

Shibuya, H., Merrill, D.L., Hsu, V., and Leg 124 Shipboard Scientific Party, 1991. Paleogene counterclockwise rotation of the Celebes Sea-orientation of ODP cores utilizing the secondary magnetization. In Silver, E.A., Rangin, C., von Breymann, M.T., et al., Proc. ODP, Sci. Results, 124: College Station, TX (Ocean Drilling Program), 519-523.

Stokking, L.B., Musgrave R.J., Bontempo, D., and Autio, W., 1993. Handbook for Shipboard Paleomagnetists. ODP Tech. Note, 18: College Station, TX (Ocean Drilling Program).

Sutherland, H.E., Calvert, S.E., and Morris, J.R., 1984. Geochemical studies of the recent sapropel and associated sediment from the Hellenic Outer Ridge, eastern Mediterranean Sea, I. Mineralogy and chemical composition. Mar. Geol., 56:79-92.

Tauxe, L., Valet, J.-P., and Bloemendal, J., 1989. Magnetostratigraphy of Leg 108 advanced hydraulic piston cores. In Ruddiman, W., Sarnthein, M., et al., Proc. ODP, Sci. Results, 108: College Station, TX (Ocean Drilling Program), 429-439.

Tucker, P., 1980. Stirred remanent magnetization: a laboratory analogue of post-depositional realignment. J. Geophys., 48:153-157.

Verosub, K.L., and Roberts, A.P., 1995. Environmental magnetism: past, present, and future. J. Geophys. Res., 100:2175-2192.

Weeks, R.J., Laj, C., Endignoux, L., Fuller, M.D., Roberts, A.P., Manganne, R., Blanchard, E., and Goree, W., 1993. Improvements in long-core measurement techniques: applications in palaeomagnetism and palaeoceanography. Geophys. J. Int., 114:651-662.

Weeks, R.J., Roberts, A.P., Verosub, K.L., Okada, M., and Dubuisson, G.J., 1995. Magnetostratigraphy of upper Cenozoic sediments from Leg 145, North Pacific Ocean. Proc. ODP, Sci. Results, 145: College Station, TX (Ocean Drilling Program), 491-521.

\section{Ms 160IR-115}

